\title{
Swine flu breaks out on Vancouver Island
}

$\mathrm{T}$

he first pandemic (H1N1) 2009 outbreak of Canada's fall flu season has occurred within remote Aboriginal communities on Vancouver Island in British Columbia, CMAJ has learned.

Tofino, BC, family physician Dr. John Armstong says he has treated "dozens" of people infected with the virus, while the outbreak is such that the province's public health lab in Vancouver recently instructed him to stop sending swabs, having confirmed that all of the samples he had already forwarded were, in fact, positive for the H1N1 virus.

"We've reduced our swabbing because we know that everyone who has flu-like illness in this area right now has H1N1," Armstrong says. BC public health officials "more or less told us to stop taking swabs because the lab is getting swamped in Vancouver."

Armstrong says most of the cases he's handled have been "fairly mild" and treatable with oseltamivir (Tamiflu), with only two patients - an infant and an adult over 50 years of age requiring hospitalization. "Most of the people I have been seeing are younger adults, between 20 and 40, some teenagers."

The largest outbreak occurred in Ahousat, the principal settlement on Flores Island, which is accessible only by water or air. Ahousat is also one of the main settlements of the Ahousaht First Nations led by hereditary chief Shawn Atleo, who was recently elected national chief of the Assembly of First Nations.

But a "big community effort kept a lid on that," as Aboriginal leaders and health officials held public meetings and urged measures to contain the spread, Armstrong says. "But now that school is starting, it's changed again. We're also seeing the same flu patterns in other communities."

Armstrong says there has not been a flu-related death within the area he serves: Tofino and the nearby communities of Hot Springs Cove and Ahousat. But another BC doctor says

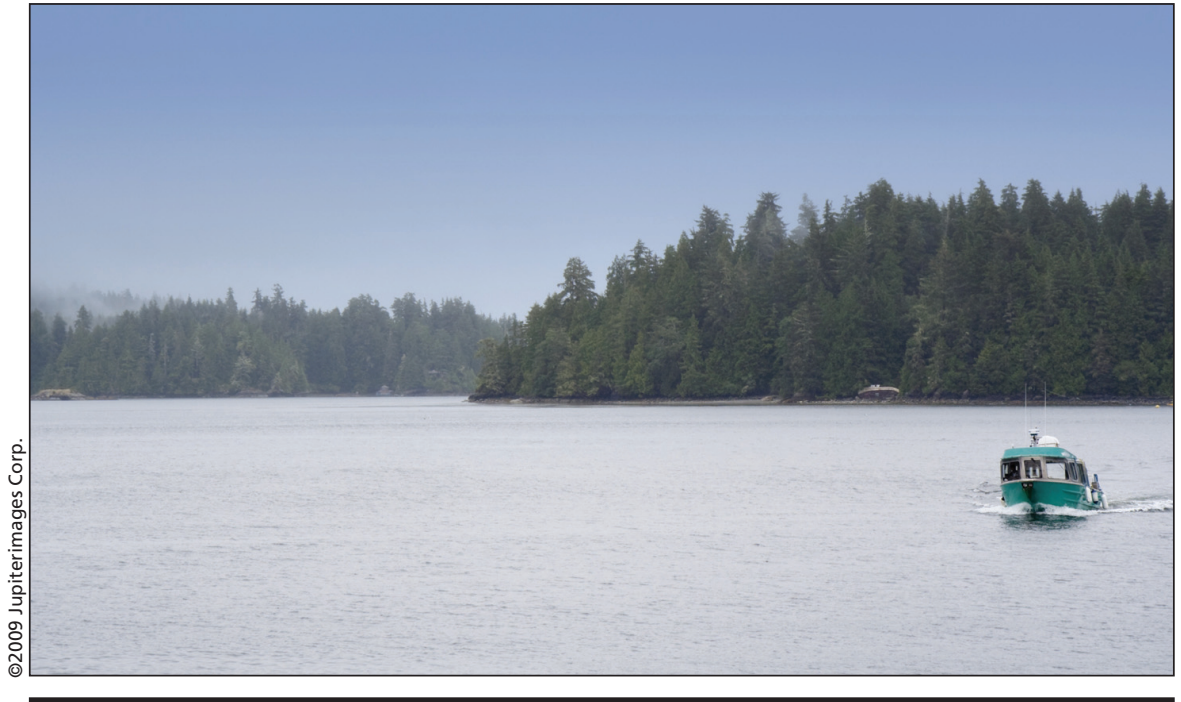

The centre of the pandemic (H1N1) 2009 flu outbreak has occurred in a community that is only accessible by water or air.

privately that one Vancouver Island death is "suspected" as being caused by H1N1, although "it is not yet officially confirmed by health authorities in Vancouver."

Although it has been argued that federal and provincial public health officials must loosen restrictions on distributing oseltamivir in remote communities where no physician or registered nurse is readily available on a daily basis, Armstrong says there's a balance to be struck.

"Somebody has to make the clinical diagnosis in time," he says. "Who is going to make that clinical diagnosis? The problem is that flu symptoms can look an awful lot like some other things. One of them is kidney infection. You get fever, chills, aches and pains with that. Or tonsillitis, sore throat, fever, aches and pains, headaches. Those are things that you get with influenza. The danger is that you give Tamiflu to somebody when they should be treated for appendicitis, or kidney infection, and actually causes harm because you've deferred proper diagnosis."

"On the other hand, when there's a high epidemiological likelihood of that person having the flu, it's running through the household, I don't see there's any reason why community health nurses can't be dispensing it. This really brings up the issue of access to care for people in remote places."

The outbreak also raises concerns about the availability of a pandemic (H1N1) 2009 flu vaccine. The US Food and Drug Administration approved a vaccine, clearing the way for vaccinations to commence in early October. In Europe, vaccinations commenced in September.

Canadian health officials, meanwhile, have provided no indication whatsoever of when a vaccine might actually be available north of the 49th parallel, beyond saying it "might" be available in mid-November. The Public Health Agency of Canada did, however, announced that pregnant women, health workers, residents of remote area and adults with chronic conditions will be given "priority" access to a vaccine when it becomes available.

Given that a vaccine isn't available, Armstrong says, it's important that Tamiflu be "prepositioned" and readily available to those infected with the virus. - Wayne Kondro, CMAJ

DOI:10.1503/cmaj.109-3054 